\title{
ResearchOnline@JCU
}

This is the author-created version of the following work:

Ramsay, Jonathan E., Tong, Eddie M.W., Chowdhury, Avijit, and Ho, Moon-Ho

R. (2019) Teleological explanation and positive emotion serially mediate the effect of religion on well-being. Journal of Personality, 87 (3) pp. 676-689.

Access to this file is available from:

https://researchonline.jcu.edu.au/54853/

(C) 2018 Wiley Periodicals, Inc. Accepted Version: this article may be used for noncommercial purposes in accordance with Wiley Terms and Conditions for Use of Self-Archived Versions.

Please refer to the original source for the final version of this work: 
DR. JONATHAN EDWARD RAMSAY (Orcid ID : 0000-0003-4634-9040)

Article type : Original Manuscript

Teleological Explanation and Positive Emotion Serially Mediate the Effect of Religion on Well-Being

Jonathan E. Ramsay

James Cook University

Eddie M. W. Tong, Avijit Chowdhury

National University of Singapore

Moon-Ho R. Ho

Nanyang Technological University

Author Note

Jonathan E. Ramsay, College of Healthcare Sciences, James Cook University, Singapore; Eddie

M. W. Tong, Department of Psychology, Faculty of Arts and Social Sciences, National University of

Singapore; Avijit Chowdhury, Department of Psychology, Faculty of Arts and Social Sciences, National

University of Singapore; Moon-Ho R. Ho, Psychology Programme, School of Social Sciences, Nanyang

Technological University.

Correspondence concerning this article should be addressed to Jonathan E. Ramsay, College

of Healthcare Sciences, James Cook University, 149 Sims Drive, Singapore, 387380. Email:

jonathan.ramsay@jcu.edu.au

This article has been accepted for publication and undergone full peer review but has not been through the copyediting, typesetting, pagination and proofreading process, which may lead to differences between this version and the Version of Record. Please cite this article as doi: 10.1111/jopy.12425

This article is protected by copyright. All rights reserved. 


\begin{abstract}
Objective: Previous research has demonstrated a robust relationship between religion and wellbeing, and it has been proposed that positive emotions are important mediators of this effect. Yet the mechanism via which religion promotes positive emotions has not been widely studied. We sought to examine whether teleological explanations of daily events and resulting positive emotions serially mediated the effects of religion on well-being.

Method: These hypotheses were tested over three studies. In study 1, participants completed measures of religiousness and well-being, and explained and described three recent personally significant events and their resulting emotions. Studies 2 and 3 adopted an ecological momentary assessment approach to measure teleological explanations, resulting emotions, and well-being in almost real time.
\end{abstract}

Results: In study 1, teleological explanations and positive emotions serially mediated the effects of religiousness on well-being. In study 2 , momentary teleological explanations of daily events mediated the positive relationship between religiousness and the momentary positive emotions. In Study 3 , serial mediation of the relationship between religiousness and momentary well-being by momentary teleological explanations and positive emotions was observed.

Conclusions: These results provide evidence of the importance of teleological explanations of daily events in religious enhancement of well-being.

Keywords: religion, teleological explanations, positive emotions, well-being, ecological momentary assessment

\title{
Introduction
}

Anecdotal evidence suggests that religious individuals often attribute their happiness to faith, and the relationship between religious belief and well-being has received considerable attention in the psychological literature. Many studies have demonstrated positive associations

This article is protected by copyright. All rights reserved. 
between religion and well-being (Koenig, King, \& Carson, 2012), and the global and historical pervasiveness of religious belief and identification (Boyer, 2001) suggests that religion plays an important role in determining the quality of human experience.

Many researchers have attempted to provide a mechanistic account of the relationship between religion and positive individual outcomes such as enhanced well-being. Historically, these candidate mediators have fallen into one of two categories: social resources and cognitive resources (Van Cappellen, Toth-Gauthier, Saroglou, \& Fredrickson, 2016). Social resources such as participation in collective rituals and identification with religious groups are interpersonal in nature, suggesting that religious enhancement of well-being results from satisfaction of fundamental social needs for affiliation and relatedness (Koestner \& McClelland, 1992; Ryan \& Deci, 2000).

Cognitive resources are more intrapersonal, pertaining to the way that religious belief influences an individual's interpretation of their experiences. Religious or spiritual worldviews can imbue events with a sense of meaning or coherence by embedding them in larger cosmic narratives (Dendy, 2015), which may in turn promote well-being. Such mechanisms are particularly influential in the case of extreme negative events such as personal tragedy, where religious belief has often been found to serve as an effective coping mechanism (Pargament, Ensing, Falgout, Olsen, Reilly, Van Haitsma, \& Warren, 1990). This buffering against the detrimental effects of adverse circumstances appears to be an important way that religion and spirituality promote well-being.

Recently, researchers in the field have begun to investigate the importance of a third class of mediators: emotional resources. Adopting the broaden-and-build perspective (Fredrickson, 2001), researchers have gathered evidence that positive emotions mediate the effects of religiosity and spirituality on well-being (Van Cappellen et al., 2016). This account is consistent with other research showing that religion can enhance positive emotions (Fredrickson, 2002), although it is worth noting the effects of religion on positive emotions are likely reciprocal (Van Cappellen, Saroglou, Iweins, Piovesana, \& Fredrickson, 2013).

This article is protected by copyright. All rights reserved. 
It is unlikely that these three mediating mechanisms operate independently. Indeed, the cognitive and emotional mechanisms are particularly likely to be deeply intertwined. Appraisal theories propose that emotions arise as a result of cognitive interpretations of events along dimensions such as goal relevance, goal congruence, certainty, coping potential, and agency (Moors, Ellsworth, Scherer, \& Frijda, 2013), with the nature and valence of the emotion being determined by the pattern of appraisal. Religious and spiritual beliefs seem to have important effects on appraisal process, with religious individuals often invoking divine causation or purpose when appraising a significant life event (Pargament, Olsen, Reilly, Falgout, Ensing, \& Van Haitsma, 1992), especially when those events are positive and life-altering (Lupfer, Tolliver, \& Jackson, 1996; Riggio, Uhalt, \& Matthies, 2014). Such benevolent appraisals are predictive of positive mental health outcomes (Pargament, Koenig, Tarakeshwar, \& Hahn, 2004), and it is likely that attenuation of negative emotions and promotion of positive emotions plays a significant role in this process.

The importance of appraisals of meaningfulness in the link between religion and well-being has been highlighted by several studies. Steger and Frazier (2005) found that meaning in life mediated the effect of religiousness on life satisfaction, as well as the relationship between daily religious behaviours and well-being. Adopting a longitudinal approach, Kashdan and Nezleck (2012) investigated the relationships between spirituality, meaning in life, self-esteem and generalised positive affect in a daily diary study, finding that the linkages between daily spirituality and both selfesteem and generalised positive aspect were both fully mediated by meaning in life. Furthermore, these interrelationships were found to be stronger among individuals higher in trait spirituality.

However, despite the plausibility of these connections, the sequential link between religious belief, interpretation of events, resulting emotions, and well-being has not yet been examined in its entirety. The present research sought to address this issue and provide a more detailed account of the link between religion and well-being by simultaneously examining the role of both cognitive and emotional mediators. Specifically, we investigated the extent to which religion promotes appraisals of meaning, purpose, and significance in response to daily events-hereafter referred to as

This article is protected by copyright. All rights reserved. 
teleological explanations - and whether such explanations enhance the experience of relevant positive emotions, particularly gratitude and contentment. Finally, we also sought to establish whether increased experience of transient positive emotions is consolidated as more stable enhancements in overall well-being.

\section{Religion and Teleological Explanation}

All world religions believe that the universe has an underlying order and structure that provides events and states-of-being with greater meaning or significance. Often referred to as teleological reasoning, the tendency to attribute significance to events is not uniquely religious, although religious individuals have been shown to hold stronger teleological beliefs than nonbelievers (Banerjee \& Bloom, 2014). Although teleological reasoning has been proposed as a general cognitive bias, it has been suggested that culturally transmitted ideas such as religious belief augment this attribution style (Banerjee \& Bloom, 2014; Heywood \& Bering, 2014). As such, it seems that religious belief should promote teleological explanation of events and circumstances. If the religious believer interprets events in a teleological fashion, one interesting question is how that influences the individual's emotional reaction to those events. As we argue in the following sections, it seems likely that religiously inspired teleological explanations should enhance the experience of positive emotions in particular.

\section{Religion, Positive Emotions, and Well-Being}

Emmons (2005) has identified several characteristics of religious or sacred emotions: (a) they are more likely to occur in religious settings, (b) they occur to a greater extent in individuals who profess a belief in believers compared to non-believers, and (c) they arise from perception of sacred elements in life events. While such emotions are also experienced by those who do not believe in the divine, it is argued that religious belief enhances the frequency and intensity of such emotional experiences.

This article is protected by copyright. All rights reserved. 
One emotion that has garnered special attention in this regard is gratitude. All major religions view gratitude as a key component of the religious experience and as a necessary emotional response to divine provenance (e.g., 2 Corinthians 4:15; Ibrahim 14:7; Anguttara Nikaya 2.118), while scholars have identified gratitude as a positive affective hallmark of religiously and spiritually engaged people (Watkins, Woodward, Stone, \& Kolts, 2003). Gratitude has been shown to have a positive association with both religious belief (Krause, 2009; McCullough, Emmons, \& Tsang, 2002; Lambert et al., 2009) and well-being (see Wood, Froh, \& Geraghty, 2010, for a review), and daily spiritual experiences have been found to mediate the effects of religious practice on the experience of positive emotions, gratitude included (Hardy et al., 2014). Importantly, gratitude has also been shown to mediate the relationship between religion and well-being (Van Cappellen et al., 2016), illustrating the key role of certain positive emotions in the connection between religious belief and well-being. While gratitude also has cognitive and behavioral aspects, it is often characterised as an emotion with important moral and prosocial ramifications (McCullough \& Tsang, 2004). In this paper we focus on the emotional experience of gratitude while acknowledging the importance of associated cognitions and behaviors.

Contentment is another positive emotion that has been proposed to have links with both religiosity/spirituality and well-being. Fredrickson (2002) asserts that the experience of contentment encourages individuals to savour their current life circumstances, and to attempt to integrate these circumstances into new views of both the self and of the world at large. Suppression of human or earthly desires is a doctrine in many major world religions (Durkheim, 1912), and finding contentment could potentially allow religious individuals to resist the temptation to pursue religiously inconsistent goals. Consistent with the notion that contentment is a sacred emotion (Emmons, 2005), many researchers have identified contentment as one of several positive emotions that may mediate the effects of religion on well-being (Ellison, Musick, \& Henderson, 2008; Seybold \& Hill, 2001), and as a core component of spiritual experience (Piedmont, 2001).

This article is protected by copyright. All rights reserved. 


\section{Examining Religion in Everyday Life}

Beyond the mechanistic elucidation described above, this research also sought to make another important contribution to the literature: examining the influence of religion on explanatory style, emotion, and well-being in everyday life. While calls for greater ecological validity in psychological research are nothing new (Orne, 1962), there have been recent calls for placing a greater emphasis on ecological validity in psychological investigations of religious processes (Exline, 2012). Ecological momentary assessment (EMA; Stone \& Shiffman, 1994) methods can go a long way to improving ecological validity. While several longitudinal investigations of religion, emotion, and well-being have employed daily diary studies (e.g., Kashdan \& Nezleck, 2012), only a few have applied this technique to examine daily fluctuations in religiosity and positive emotions (e.g., Hardy et al., 2014), and none have used EMA techniques to investigate the relationships between religion and momentary cognition, emotion, and well-being.

Our adoption of EMA also enabled us to improve the representativeness of the experiences we assessed. Previous research examining the effects of religion on interpretation of events have usually focused on major, life-altering events, such as a heart attack (Riggio et al., 2014), moving to a new city (Lupfer, Tolliver, \& Jackson, 1996), or the breakdown of a relationship (Ray, Lockman, Jones, \& Kelly, 2015), and have generally found that religious individuals invoke religious or teleological explanations when attributing causality. In the present research we sought to extend this line of reasoning to more mundane events; investigating whether religious individuals truly see divine influence in their daily lives, and whether this affects their experience of both positive emotions and resulting well-being. While the influence of religion on reactions to life-altering events is undoubtedly an important topic for research, we argue that it is equally important to investigate how religious belief influences cognition and emotion in daily life. This was a primary intent of the present investigation.

This article is protected by copyright. All rights reserved. 


\section{The Present Research}

The present research comprised three studies. In study 1 we adopted a single time-point correlational design to conduct a preliminary investigation of the relationships between religion, teleological explanation, religious or "sacred" positive emotions (specifically gratitude and contentment), and well-being. In study 2, we extended this research by using EMA techniques to examine the effects of religion on momentary teleological explanations and these same two positive emotions over a one-week period. In study 3, we sought to replicate and extend the findings of study 2 by using the same EMA methodology to investigate the effects of religion on momentary teleological explanation, gratitude and contentment, and also well-being. In each case, we expected to observe a positive effect of religion on well-being that was serially mediated by two intervening variables: teleological explanation and the aforementioned positive emotions.

\section{Study 1}

\section{Method}

\section{Participants}

A total of 120 participants from a large Singapore university took part in study 1 in return for partial course credit. Due to a technical error in survey administration, demographic data were only recorded for 103 of the 120 participants. The subsample of participants that contributed demographic data was $66 \%$ female with a mean age of 30.50 years $(S D=10.06)$. Participants were all part-time undergraduate psychology students, the majority of whom were adults in full-time employment, meaning that a wide range of ages was represented. The youngest participant was 21 years of age while the oldest was 67 . The majority of the participants were ethnically Chinese (56.3\%) with Malays (23.3\%), ethnic Indians (15.5\%) and other ethnic groups (4.9\%) making up the remainder of the sample. The sample was heterogeneous in terms of religious identification. Religious affiliation amongst the participants was diverse with Protestant/Catholic (27.05\%), Buddhists or Taoist (29.8\%), Muslim (26.23\%), and Hindu (2.46\%) religious group represented.

This article is protected by copyright. All rights reserved. 
$25.41 \%$ of the participants identified as having no religious affiliation. All studies were approved by the Singapore University of Social Sciences ethics committee, and all participants provided informed consent before completing the questionnaire.

The required sample size for study 1 was estimated by following the guidelines provided by Fritz and Mackinnon (2007). Assuming a simpler model with a single mediating variable, Fritz and Mackinnon calculated a required sample size of between 71 and 78 to achieve power of .8 when (a) both the alpha and beta paths were moderately sized, and (b) mediation was tested using bootstrapping methods. Although our proposed serial mediation model was more complex, we sought to minimize the risk of conducting an underpowered study by increasing the target sample size to 100 participants.

\section{Materials}

Personally significant events. Participants were asked to think of three significant events that happened to them in the past week. They were instructed that the events can be either positive or negative, but that they must be of some personal significance. In each case, they were required to write a paragraph describing the event, before completing the measures described in the subsequent sections.

Teleological explanations. After each describing each event, participants were required to indicate the extent to which they explained the event teleologically by rating their agreement with three statements-(a) "I believe this event was meant to be", (b) "I believe this event happened for a reason" and (c) "I believe this event happened to send me a message" - on seven-point response scales anchored at strongly disagree and strongly agree. The Cronbach's $\alpha$ of this scale across the three events ranged from .83 to .86 .

Event-contingent emotions. Participants were also asked to indicate the extent to which they experienced eight emotions in response to the event. All emotion words were endorsed on a five-point Likert scale anchored at not at all and extremely. Four emotion words corresponded to gratitude (grateful, thankful, ungrateful, resentful), while the other four corresponded to

This article is protected by copyright. All rights reserved. 
contentment (contented, satisfied, discontented, unsatisfied). In each case the latter two items were reverse scored. The reliabilities of the gratitude and contentment scales ranged from .82 to .84 and from .89 to .90 , respectively. When collapsed into a single scale measuring aggregate positive emotion, the reliabilities were even higher: .93 for each of the three events.

Well-being. Well-being was measured using a single item. Participants were asked to indicate how they felt about their life as a whole over the past week on a seven-point scale anchored at terrible and delighted.

Religiousness. The religiousness of participants was measured using several measures detailed in the Multidimensional Measurement of Religiousness/Spirituality (MMRS; Fetzer Institute/National Institute on Aging Working Group, 1999). The MMRS is a multidimensional collection of well-validated measures of both religiosity and spirituality, which captures these highly correlated yet distinct aspects of religious observance and experience (Smith \& Denton, 2005).

In the present research, we chose to measure the following dimensions of religiousness and spirituality: daily spiritual experiences (DSE), religious values/beliefs (VB), private religious practice (PRP), and communal religious practice (CRP). These were chosen because they capture the cognitive, attitudinal, and behavioral components of religiousness and spirituality. Given that the various measures of religiousness/spirituality were highly inter-correlated ( $r$ ranging from .60 to .84), responses were aggregated into a single variable. This was done by first standardizing the measures of religiosity/spirituality and then computing the mean of the standardized variables. The resulting composite variable was used in the subsequent analyses. Although this practice does to some extent conflate religiosity and spirituality, we believe it is justified on the grounds that (a) the aggregate variable better represents the totality of what it means to be religious, and (b) the two have previously been found to be highly concordant (Day, 2010), a finding that is borne out by the strong correlations observed in the present research. The term religiousness is used throughout this paper to refer to a combination of both religiosity and spirituality; a practice with ample precedent in the literature (e.g., Steger \& Frazier, 2005).

This article is protected by copyright. All rights reserved. 


\section{Design and Procedure}

All measures in study 1 were administered online. After providing consent, participants were instructed to think of three significant events that happened to them in the past week. Thereafter they described each event in turn, first completing the measures of teleological explanation and event-contingent emotions, before repeating the procedure for the next event. After all three events were complete, they indicated their well-being, and completed the measure of religiosity and spirituality, as well as several other measures that are not the focus of the present analysis. At the end of the study, participants were presented with the debriefing information and rewarded with their course credit.

\section{Results \& Discussion}

Average teleological explanation was calculated by averaging the responses to the three items for each event and then averaging across the three events. Average gratitude and contentment were calculated using a similar method. Table 1 shows the descriptive statistics and correlations between the variables measured in study 1 .

The overall measure of religiousness was positively correlated with all measured variables. Event-contingent teleological explanation of events (teleology) was positively correlated with all other variables except well-being. All other variables were also mutually positively correlated. Of particular interest was the strong correlation between average event-contingent gratitude and contentment (.913), which suggested that participants perceived these subtly different positive emotions to be extremely similar. This is also supported by the results of the reliability analysis reported earlier, whereby the scales comprising all eight emotion items (four for gratitude, four for contentment) exhibited greater internal consistency than any of the four-item gratitude or contentment scales. Consequently, we chose to collapse the gratitude and contentment variables into a single positive emotion variable in the subsequent mediation analyses. This practice was repeated in the second and third studies.

This article is protected by copyright. All rights reserved. 
Despite the religiously heterogeneous nature of our sample, cell sizes in study 1 were not large enough to permit separate analysis of the various religious groups. This was also true of studies 2 and 3. This represents a limitation of the research and is further elaborated upon in the discussion section.

Mediation analyses. To test our hypotheses, we conducted mediation analyses using the SPSS PROCESS macro (Hayes, 2012). The SPSS PROCESS macro calculates $95 \%$ Confidence Intervals as test of indirect effect using non-parametric boot-strap methods. As per our research question, we tested a sequential mediation model in which religiousness influences well-being via teleological explanations and then positive emotions. This general model is illustrated in figure 1.

We tested the hypothesized serial mediation of the effect of religiousness on well-being via teleological explanations of daily events and event-contingent positive emotions. Results indicated that the direct effects represented by paths $a, b$, and $d$ in figure 1 were all positive and statistically significant. Similarly, the direct effect represented by path $f$ was also found to be significant, indicating a positive direct effect of religiousness on well-being. More confusingly, and contrary to our hypotheses, results indicated a significant and negative direct effect of teleological explanations on well-being (path $e$ ). However, the indirect effect of religiousness on well-being via the two serial mediators (path $\left.a^{*} b^{*} d\right)$ was also found to be both positive and significant $(95 \% \mathrm{Cl}[.052, .213])$, while of the two indirect paths that omitted one of the hypothesized mediators (paths $a^{*} e$ and $c^{*}$ d), only $a^{*} e$ was found to be significant. These results imply partial mediation of the effect of religiousness on well-being via teleological explanation and positive emotions. Results indicated that the mediators accounted for $40 \%$ of the overall effect of religiousness on well-being $\left(P_{\mathrm{M}}=.399\right)$. The unstandardized parameter estimates, standard errors, $t$-statistics, $p$ values of the direct effects and 95\% confidence intervals for indirect effects in this model are reported in table 2.

This article is protected by copyright. All rights reserved. 


\section{Study 2}

In the first study, participants' recollections of events, teleological explanations, and emotional reactions were all assessed post-hoc. While the phrasing of the instructions should have encouraged participants to recall events that were representative and typical of daily life, welldocumented memory biases such as the Von Restorff effect (e.g., Fabiani \& Donchin, 1995) may have caused participants to recall events that were more significant, impactful, or unusual than those that usually constitute daily life. In order to ameliorate such effects and to more accurately sample daily experience, studies 2 and 3 adopted an EMA design to minimise the delay between experience and assessment. Study 2 was designed to investigate whether momentary teleological explanations of events mediated the effect of religiousness on momentary experiences of positive emotions, while study 3 sought to investigate the hypothesised serial mediation of the effects of religiousness on momentary well-being, via momentary teleological explanation and positive emotion.

\section{Method}

\section{Participants}

A total of 111 participants took part in study 2 . All participants were students at the same university as in study 1 . The sample was $68.47 \%$ female with a mean age of 28.09 (SD $=8.25$ ). The majority of the participants were ethnically Chinese (63.06\%) with Malays (24.32\%), ethnic Indians (8.11\%), and other ethnic groups (4.50\%) making up the remainder of the sample. As before, the sample was heterogeneous in terms of religious identification, with Christians/Catholics (28.83\%), Buddhists/Taoists (20.72\%), Muslims (27.93\%), and Hindus (3.60\%) all represented. 18.92\% of the participants identified as having no religious affiliation. Given the complexity of computing power in multilevel designs, we did not conduct formal power calculations in studies 2 and 3 . Nevertheless, we followed the recommendation of Maas and Hox (2005) to sample at least 50 observations at

This article is protected by copyright. All rights reserved. 
level 2 (in this case the level of the individual) to avoid biased estimates of standard errors. Our obtained sample sizes of 111 (study 2) and 76 (study 3) comfortably exceed this recommendation.

\section{Materials}

Religiousness. As in study 1, all participants completed measures of daily spiritual experiences (DSE), religious values/beliefs (VB), private religious practice (PRP), and communal religious practice (CRP). A composite religiousness variable was once again computed following the same procedure used in study 1 . Religiousness was measured once at baseline, whereas all other constructs were measured multiple times over the course of the data collection period.

Daily events. In study 2 we wished to assess emotional reactions to events in (almost) realtime. As such, the wording of the questions used to solicit this information was necessarily different from that used in study 1. Participants were asked to "think of a significant event that happened to you in the past hour or so". Participants were told that the event could be either positive or negative, but that it must be of some personal significance to them.

Positive emotions. Participants indicated their emotional responses to each event on 5-point scale anchored at not at all and extremely. As in study one, participants were asked to indicate how much each event caused them to experience the eight different emotional states: four corresponding to gratitude (grateful, thankful, ungrateful, resentful) and four corresponding to contentment (contented, satisfied, discontented, unsatisfied). Given the extremely high correlation between the composite gratitude and contentment variables in study 1 , these eight emotion items were used to compute a single positive emotion variable, with responses to negatively worded items being reverse-scored prior to computation.

Teleological explanations. Participants completed the same measure of teleological explanation used in study 1 . For each event they were asked to indicate their agreement with the following statements on a 7-point scale anchored at strongly disagree and strongly agree: (a) "I believe this event was meant to be", (b) "I believe this event happened for a reason" and (c) "I

This article is protected by copyright. All rights reserved. 
believe this event happened to send me a message". Responses to these items were averaged to provide an aggregate measure of teleological explanation.

\section{Design}

The study adopted a longitudinal, correlational, multi-level design in which participants were first required to complete a baseline measure of religiousness using the procedure described previous section. This variable was conceived as being both stable and trait-like, as it was in study 1 . After completing the baseline measure package, which also included demographic items, participants began a one-week assessment EMA period during which they were surveyed a total of 21 times: three times each day for seven consecutive days. Personal events, teleological explanations, and positive emotions were assessed in each and every EMA survey.

The design of the study and the resulting data were hierarchical in nature. Momentary observations of personal events, teleological explanations, and positive emotions (level one variables) were nested in individual participants. Religiousness was measured at the level of the individual, and therefore constituted a level two variable. This corresponded to a "2-1-1" multi-level mediation model (Hayes, 2012), in which the independent variable (religiousness) was hypothesized to influence the dependent variable (momentary positive emotions) via a mediating variable (momentary teleological explanations).

\section{Procedure}

Consenting participants were sent a link to the survey containing the participant information sheet, consent form and the baseline measures, and were informed that they would be asked questions about their attitudes, beliefs and personality. Participants were also told that during the following week they would be sent a total of three survey links per day, which would be disseminated at random points anywhere between 9am and 9pm, and that these surveys would require them to answer some questions about events in their daily lives and how they felt about them. They were also informed that there would be a second phase of data collection three months after this initial phase.

This article is protected by copyright. All rights reserved. 
During the one-week EMA period, we used an online survey administration platform to email the survey link to the participants. Participants were divided into nine administration groups, and surveys emails were disseminated at pseudo-random timings that were specific to each group. Each day, the 12 hour period between 9am and 9pm was divided into three blocks - "morning", "afternoon", and "evening" - and a computer programme was used to randomly select a single time point in each of these three blocks. This was done separately for each of the nine groups, meaning that there was considerable variability in survey administration timing: both between participants on a given day and between days for a given participant. This was intended to provide a richer and more varied sample of personal experiences. Participants were instructed to complete the EMA recordings in response to these emails as soon as they received them. Each survey email was also accompanied by a message on the popular messaging service WhatsApp that served to notify participants that a response was required. Completion rates were regularly monitored, and reminder emails and WhatsApp messages were sent whenever a participant failed to respond.

At the end of study 2, participants were awarded with their course credit and reminded that they will be contacted in another three months' time for a second phase of data collection.

\section{Results \& Discussion}

Descriptive statistics for the key variables in study 2 can be found in table 3 . Using individual EMA assessment points as the unit of analysis, religious individuals (those who indicated religious identification) invoked more teleological explanations than non-religious individuals (those who indicated no identification with a religion); $t(2206)=9.91, p<.001$; and also experienced more positive emotions; $t(2149)=2.99, p=.003$. Given that momentary teleological explanations were measured on a 7-point scale with a score of four corresponding to the midpoint, the mean score of 4.78 indicated that religious participants generally invoked teleological explanations for mundane daily occurrences (a score of 5 corresponds to the label of somewhat agree). This was less true of the non-religious individuals $(M=3.95)$.

The study 2 data were further analysed by testing a multi-level mediation model using

This article is protected by copyright. All rights reserved. 
Mplus (Muthén \& Muthén, 1998-2015). The mediation model, depicted in figure 2, represents a simpler version of the model tested in study 1 , as only the first two links in the hypothesized chain were tested. Our hypothesis was that momentary teleological explanations would mediate the effect of religiousness on momentary experience of positive emotions. The test of an indirect effect for multilevel mediation in Mplus is based on asymptotic normal theory (standard errors for the indirect effect estimates are derived by multivariate delta method). The unstandardized parameter estimates, standard errors, $p$ values, and $95 \%$ confidence intervals of the different paths between variables in this model are reported in table 4 . In support of our hypothesis, momentary teleological explanations of daily events mediated the positive relationship between religiousness and the momentary experience of event-contingent positive emotions. The direct effect of religiousness on momentary positive emotions was non-significant yet the indirect effect via momentary teleological explanations was, implying mediation.

\section{Study 3}

In study 3 we sought to replicate and extend the findings of studies 1 and 2 by conducting a further EMA study. The major difference between this study and the previous one was the inclusion of an additional EMA variable, well-being, which represented the final link in the hypothesised causal chain. In many ways, study three also represented a replication of the model tested in study 1 , but with teleological explanations, positive emotions, and well-being all being assessed momentarily rather than retrospectively.

\section{Method}

\section{Participants}

As described previously, the participants in study 3 were a subsample of those who took part in study 2 . All study 2 participants were encouraged to continue their involvement, although only 76 of the original 111 participants chose to do so. This figure represents an attrition rate of $31.5 \%$ between studies 2 and 3 . The resulting sample was $67.11 \%$ female with a mean age of 27.80 (SD =

This article is protected by copyright. All rights reserved. 
8.08). As in the previous two studies, the majority of the participants were ethnically Chinese (60.53\%) with Malays (27.63\%), ethnic Indians (9.21\%), and other ethnic groups (2.63\%) making up the remainder of the sample. Religious affiliation amongst the participants was once again diverse with Christians/Catholics (25.00\%), Buddhists/Taoists (21.05\%), Muslims (30.26\%), and Hindus (2.63\%) all represented. $21.05 \%$ of the participants identified as having no religious affiliation. The study was approved by the Singapore University of Social Sciences ethics committee. All participants who completed all the surveys in study 3 were entered into a lucky draw to win a prize of $\$ 200$ (SGD) in shopping vouchers. The winner of this prize was chosen at random.

\section{Materials}

All study 3 measures were the same as those used in study 2, with one notable exception.

The EMA surveys in study 3 included an additional item that was designed to assess momentary well-being. This single-item measure was included at the end of each EMA survey, immediately after the momentary emotion items. Participants were asked "At the present time, how do you feel about your life as a whole?", and invited to respond using a 7-point scale anchored at terrible and delighted.

\section{Design \& Procedure}

The design and procedure of study 3 were identical to those used in study 2 .

\section{Results \& Discussion}

Descriptive statistics for the key variables in study 3 can be found in table 3 . Those participants who participated in both studies 2 and 3 did not differ significantly from those who participated only in study 2 in terms of any of the key baseline measures of religiousness ( $p$ values for independent samples $t$ tests ranged from .54 to .86$)$.

Using individual EMA assessment points as the unit of analysis, religious individuals were again found to invoke more teleological explanations than non-religious individuals; $t(1409)=10.47$, $p<.001 ;$ and also experienced more positive emotions; $t(1409)=5.39, p<.001$. These results replicate those observed in the study 2 analysis. Furthermore, religious individuals were also found

This article is protected by copyright. All rights reserved. 
to report higher levels of momentary well-being than non-religious individuals; $t(1409)=2.38, p=$ .002 .

Most importantly, the data collected during study 3 enabled us to test the serial mediation model that was initially investigated in study 1 . Specifically, we tested whether the effect of trait religiousness on momentary well-being was serially mediated by momentary teleological explanations and event-contingent momentary positive emotions. This proposed model is depicted in figure 3. As in study 2, the multilevel mediation model was tested using Mplus. The unstandardized parameter estimates, standard errors, $p$ values, and $95 \%$ confidence intervals of the different paths between the variables in this model are reported in table 4.

In support of our hypothesis, the indirect effect of religiousness on momentary well-being via momentary teleological explanation and positive emotions (path $a^{*} b^{*} d$ ) was both positive and significant $(p<.001)$, and the direct effects representing linkages in this hypothesised causal chain$a, b$, and $d$-were also found to be positive and significant. The direct effects corresponding to paths $c, e$, and $f$ were not found to be significant, which is consistent with notion of serial mediation of the relationship between religiousness and momentary well-being. The two other indirect effects were also found to be significant, which suggests that each of the two mediators may also operate independently of one another, at least to some extent.

\section{General Discussion}

Previous research has consistently demonstrated a positive association between religion and psychological well-being, and the search for mediators of this relationship has indicated the involvement of social, cognitive, and emotional factors. In the present study we sought to extend previous research in three important ways. Firstly, we sought to examine whether teleological explanations of events mediated the previously documented effects of religion on the experience of positive emotion (Fredrickson, 2002), adding further mechanistic detail to the account of religion's positive intrapersonal effects. Secondly, we examined whether religion promotes teleological

This article is protected by copyright. All rights reserved. 
explanation and meaning-making in everyday life, rather than in response to the kinds of impactful, life-altering events that have been the focus of previous research. Thirdly and finally, we sought to test a serial mediation model that provides a possible causal chain between religion and enhanced well-being; one that incorporates the teleological explanation as a key mediator of this welldocumented effect.

To these ends, we employed both single time-point (study 1) and quasi-longitudinal EMA methodologies (studies 2 and 3 ) to test our hypothesis that teleological explanation and positive emotions serially mediate the relationship between religion and well-being. The results of our three studies were consistently supportive of this hypothesis. In study one, the relationship between religiousness and well-being was found to be partially mediated by teleological explanations of events in the recent past and recollected event-contingent positive emotion. In study 2 , the relationship between religiousness and momentary event-contingent positive emotion was found to be mediated by momentary teleological explanations. Finally, the results of study 3 consolidated these two findings by demonstrating that momentary teleological explanations and momentary event-contingent positive emotions serially mediate the relationship between religiousness and momentary well-being.

These results reinforce the importance of positive emotions as mediators of the effects of religion on well-being. As previously demonstrated by Van Cappellen et al. (2016), self-transcendent positive emotions mediate the relationship between both religiousness and spirituality on the wellbeing, providing evidence that religion might promote the accumulation of well-being via broadenand-build mechanisms (Fredrickson, 2013). While our study did not examine as diverse a range of emotions as Van Cappellen et al., our results implicate explanatory style as an important precursor of enhanced positive emotion, adding additional mechanistic detail to the nascent model of religion's effects on well-being. Not only does this provide a plausible explanation for exactly how religious belief enhances the experience of positive emotion; it also emphasises the importance of considering the combined action different classes of mediators. As mentioned in the introduction to

This article is protected by copyright. All rights reserved. 
this article, social, cognitive, and emotional mediators have typically been studied in isolation. Our results suggest, perhaps unsurprisingly, that these systems are highly interdependent, with a cognitive factor (the tendency to invoke teleological explanations) having been found to operate in conjunction with an emotional factor (the experience of gratitude/contentment). It is likely that other forms of interdependence also exist, and future research should attempt to uncover these interrelationships.

One of the greatest strengths of the present research is the use of EMA methodology. By examining the immediate experience of teleological explanations, positive emotions, and well-being in naturalistic settings, we provide important insight into the ways that religious belief colours and reframes everyday experiences. While previous results have shown that faith allows religious individuals to positively reinterpret personal tragedies and other extreme negative experiences (Pargament et al., 1990), our results suggest that this capacity for reinterpretation is much more subtle and pervasive. Our results show that individuals regularly explain ostensibly unremarkable events-such as discussing hobbies with a work colleague, receiving a small but unexpected gift, or spending time with a family member-in a teleological fashion, and that religious belief facilitates this tendency. Moreover, the degree to which individuals ascribe meaning, purpose, and significance to such events associates positively with their experience of positive emotions such as gratitude and contentment. While previous research has established an important role for meaningfulness in the relationship between religion and well-being (Steger \& Frazier, 2005; Kashdan \& Nezleck, 2012), ours is the first to specifically examine the role of teleological explanation in the construction of meaning, and also the first to investigate this process in immediate, moment-to-moment experience. This not only helps to establish the types of events and experiences that are seen as being meaningful, but also reduces the influence of errors and biases that may distort the reporting of such phenomena in retrospective studies. Such influence is thought to be substantial. For example, Ptacheck et al. (1994) found that on-line self-report of coping were only modestly correlated $(r=.58)$ with retrospective recollection of the same constructs.

This article is protected by copyright. All rights reserved. 
Another strength of the present research is the diversity of the various samples. Each of the samples comprised individuals of various religious affiliations, including substantial numbers of Christians (both Protestants and Catholics), Muslims, and those who identified as non-religious. Although there has been an increase in the number of studies conducted in non-traditional samples and settings (e.g., Clobert, Saroglou, \& Hwang, 2015; Ramsay, Tong, Pang, \& Chowdhury, 2016; Yilmaz, Karadöller, \& Sofouglu, 2016), the majority of psychological research investigating religious processes is still conducted in North America and Europe, raising the issue of cross-cultural generalizability. Furthermore, the literature also suffers from an over-representation of Christian samples with relatively few investigations in predominantly non-Christian or religiously heterogeneous samples, which raises a similar question of whether all religious belief systems function in a similar way. Although we did not anticipate nor test for between-religion differences in the present study, the diversity of the sample and atypicality of the geographic and cultural setting still represents an important contribution. Our results tentatively suggest that the positive effect of religious belief on well-being via teleological explanations and resulting positive emotions is a general phenomenon that holds across religious and ethnic groups. However, since these associations may also be influenced by the specific beliefs and teachings of different religions, it would be insightful to examine whether there are inter-religious differences in the relationship between religion, teleological explanation, positive emotions, and well-being, as well as differences between individuals who profess a religious belief with those who do not. Indeed, religion has been shown to be a source of variance in the experience of both sacred and secular positive emotions (Kim-Prieto \& Diener, 2009). Future research should therefore aim to explore this research question to elucidate both the common and unique effects of religious belief on explanations and emotions for individuals of different religious affiliations and cultures.

Our design is not, however, without its shortcomings. Foremost is the adoption of a correlational design that cannot provide strong evidence for directional or causal relationships among variables. While the more stable, trait-like nature of religiousness means that it is intuitively

This article is protected by copyright. All rights reserved. 
better positioned to influence momentary explanations and emotional experiences, the results reported here do not unequivocally demonstrate the direction of the interrelationships between the four key variables, although the idea of serial mediation is strongly supported. A further possibility is that these interrelationships are reciprocal and bidirectional, meaning that stable, heightened wellbeing may promote more frequent experiences of event-contingent positive emotions, which encourage teleological explanations and in turn, strengthen religious belief. Studies have shown that the experimental induction of self-transcendental positive emotions such as awe, elevation and admiration (but not other positive emotion such as humour) leads to increased spirituality, mediated by a sense of meaning in the world (Van Cappellen, Saroglou, Iweins, Piovesana \& Fredrickson, 2013; Van Cappellen \& Saroglou, 2012). As such, it seems likely that the relationships between religion, explanatory style and positive emotions are not entirely unidirectional.

Beyond the correlational nature of our design, EMA studies such as ours have several other notable weaknesses. As with all methods based on self-report, there is always a possibility that respondents have an inaccurate or incomplete understanding of their mental states or processes (Nisbett \& Wilson, 1977), or that they are acquiescing to perceived experimenter demand (Orne, 1962). Since this was ostensibly a study about religion, teleological explanation, and emotional experience with no deception involved, some participants may have responded in ways that overstate the strength or frequency of these variables.

Another shortcoming of the present research is the limited number of emotions that were studied. We originally chose to focus on gratitude and contentment because of their intuitive relevance to teleological explanation, yet it remains a possibility that teleological explanation also promotes the experience of other positive emotions, which may also foster enhanced well-being. Additionally, the results of the present study suggest that individuals do not really perceive these emotions as being distinct, as evidenced by the extremely high correlation observed in study 1 that caused us to collapse these two variables into a single variable reflecting the two. At present, we

This article is protected by copyright. All rights reserved. 
cannot say whether any specific positive emotion is more important than any other in mediating the effects religion and teleological explanation on well-being.

Several other weaknesses and shortcoming also warrant discussion. Firstly, the single-item measure of well-being used in all three studies may not be as reliable and valid as some commonly used multi-item measures of well-being. Nevertheless, there is some evidence that single item measures of well-being and conceptually similar constructs do exhibit adequate psychometric properties (Cheung \& Lucas, 2014; Sandvik, Diener, \& Seidlitz, 1993). Secondly, the ordering of presentation of the various measures in study 1 may have meant that the teleological explanation and emotion items (administered first) may have subsequently influenced the trait measures of religiousness, although we believe that this possibility was preferable to the alternative, in which earlier administration of the religion/spirituality items may have primed participants to interpret recent events in a more teleological fashion.

\section{Conclusion}

The relationship between and religion and well-being is a robust phenomenon, and social, cognitive, and emotional factors have all been proposed as important mediators of this effect. The present research provides evidence for serial mediation by both cognitive and emotional factors, whereby religion promotes the teleological explanations of daily events, which in turn promotes event-contingent positive emotions and enhanced well-being. In addition to this more detailed mechanistic account, our results also provide evidence that religious belief allows adherents to perceive divine meaning, purpose, and significance in relatively mundane daily events, and that such interpretations associate positively with momentary experience of positive emotions and appraisals of well-being. This research sheds new light on the way in which religion exerts its positive intrapersonal effects, and attests to importance of considering the combined effects of different classes of mediators when examining such phenomena.

This article is protected by copyright. All rights reserved. 


\section{Declaration of Conflicting Interests}

The author(s) declared no potential conflicts of interest with respect to the research, authorship, and/or publication of this article.

\section{Funding}

The authors disclosed receipt of the following financial support for the research, authorship, and/or publication of this article: Preparation of this manuscript was supported by Grant RF15UC01a from the Singapore University of Social Sciences ARC Research Grant.

\section{References}

Banerjee, K., \& Bloom, P. (2014). Why did this happen to me? Religious believers' and non-believers' teleological reasoning about life events. Cognition, 133, 277-303. DOI: 10.1016/j.cognition.2014.06.017

Boyer, P. (2001). Religion explained: The evolutionary origins of religious thought. New York, NY: Basic Books.

Cheung, F., \& Lucas, R. E. (2014). Assessing the validity of single-item life satisfaction measures: results from three large samples. Quality of Life Research: An International Journal of Quality of Life Aspects of Treatment, Care and Rehabilitation, 23(10), 2809-2818. https://doi.org/10.1007/s11136-014-0726-4

Clobert, M., Saroglou, V., \& Hwang, K. K. (2015). Buddhist concepts as implicitly reducing prejudice and increasing prosociality. Personality and Social Psychology Bulletin, 41, 513-525. DOI: $10.1177 / 0146167215571094$

This article is protected by copyright. All rights reserved. 
Day, J. M. (2010). Religion, spirituality, and positive psychology in adulthood: A developmental view. Journal of Adult Development, 17, 215-229. DOI:10.1007/s10804-009-9086-7

Dendy, D. (2015). Seeing God at Work Every Day: The Forty-Day Challenge. Bloomington, IN: Westbow Press.

Durkheim, E. (1912). The elementary forms of the religious life. London, UK: George Allen \& Unwin.

Ellison, C. G., Musick, M. A., \& Henderson, A. K. (2008). Balm in Gilead: Racism, Religious Involvement, and Psychological Distress Among African-American Adults. Journal for the Scientific Study of Religion, 47, 291-309. DOI: 10.1111/j.1468-5906.2008.00408.x

Emmons, R.A. (2005). Sacred emotions. In K. Bulkeley (Ed.). Soul, Psyche, Brain: New Directions in the Study of Religion and Brain-Mind Science (pp.93-112). New York, NY: Palgrave Macmillan.

Exline, J. J. (2012). Humility and the ability to receive from others. Journal of Psychology and Christianity, 31, 40-51.

Fabiani, M., \& Donchin, E. (1995). Encoding processes and memory organization: a model of the von Restorff effect. Journal of Experimental Psychology: Learning, Memory, and Cognition, 21, 224.

Fetzer Institute / National Institute on Aging Working Group (1999). Multidimensional Measurement of Religiousness/Spirituality for Use in Health Research: A Report of the Fetzer Institute / National Institute on Aging Working Group (1st ed.). Kalamazoo, MI, USA: Fetzer Institute.

Fredrickson, B. L. (2001). The role of positive emotions in positive psychology: The broaden-andbuild theory of positive emotions. American Psychologist, 56, 218. DOI: 10.1037/0003066X.56.3.218

Fredrickson, B. L. (2002). How does religion benefit health and well-being? Are positive emotions active ingredients?. Psychological Inquiry, 13, 209-213.

This article is protected by copyright. All rights reserved. 
Fritz, M. S., \& MacKinnon, D. P. (2007). Required sample size to detect the mediated effect. Psychological Science, 18, 233-239. DOI: 10.1111/j.1467-9280.2007.01882.x

Hardy, S. A., Zhang, Z., Skalski, J. E., Melling, B. S., \& Brinton, C. T. (2014). Daily religious involvement, spirituality, and moral emotions. Psychology of Religion and Spirituality. DOI: $10.1037 / \mathrm{a} 0037293$

Hayes, A. F. (2012). PROCESS: A versatile computational tool for observed variable mediation, moderation and conditional process modeling. Retrieved from http://www.afhays.com/public/process 2012.pdf

Heywood, B. T., \& Bering, J. M. (2014). "Meant to be": how religious beliefs and cultural religiosity affect the implicit bias to think teleologically. Religion, Brain \& Behavior, 4, 183-201. DOI: $10.1080 / 2153599 \times .2013 .782888$

Kashdan, T. B., \& Nezlek, J. B. (2012). Whether, when, and how is spirituality related to well-being? Moving beyond single occasion questionnaires to understanding daily process. Personality and Social Psychology Bulletin, 38, 1523-1535. DOI: 10.1177/0146167212454549

Kim-Prieto, C., \& Diener, E. (2009). Religion as a source of variation in the experience of positive and negative emotions. The Journal of Positive Psychology, 4, 447-460. DOI:

$10.1080 / 17439760903271025$

Koestner, R., \& McClelland, D. C. (1992). The affiliation motive. In C. P. Smith (Ed.), Motivation and personality: Handbook of thematic content analysis (pp. 205-210). Cambridge, UK: Cambridge University Press.

Koenig, H., King, D., \& Carson, V. B. (2012). Handbook of religion and health. New York, NY: Oxford University Press.

This article is protected by copyright. All rights reserved. 
Krause, N. (2009). Religious involvement, gratitude, and change in depressive symptoms over time. The International Journal for the Psychology of Religion, 19, 155-172. DOI: $10.1080 / 10508610902880204$

Lambert, N. M., Fincham, F. D., Braithwaite, S. R., Graham, S. M., \& Beach, S. R. (2009). Can prayer increase gratitude? Psychology of Religion and Spirituality, 1, 139-149. DOI: $10.1037 / \mathrm{a} 0016731$

Lupfer, M. B., Tolliver, D., \& Jackson, M. (1996). Explaining life-altering occurrences: A test of the 'god-of-the-gaps' hypothesis. Journal for the Scientific Study of Religion, 35, 379-391. DOI: $10.2307 / 1386413$

Maas, C. J. M., \& Hox, J. J. (2005). Sufficient sample sizes for multilevel modeling. Methodology: European Journal of Research Methods for the Behavioral and Social Sciences, 1, 86-92. DOI:10.1027/1614-2241.1.3.86

McCullough, M. E., Emmons, R. A., \& Tsang, J. A. (2002). The grateful disposition: a conceptual and empirical topography. Journal of Personality and Social Psychology, 82, 112. DOI: $10.1037 / / 0022-3514.82 .1 .112$

McCullough, M. E., \& Tsang, J. A. (2004). Parent of the Virtues? The Prosocial Contours of Gratitude. In R. A. Emmons \& M. E. McCullough (Eds.), The Psychology of Gratitude (pp. 123-141). New York, NY: Oxford University Press.

Muthén L. K., Muthén B. O. Mplus User's Guide (Sixth Edition). Los Angeles, CA: Muthén \& Muthén; 1998-2015.

Pargament, K. I., Koenig, H. G., Tarakeshwar, N., \& Hahn, J. (2004). Religious struggle as a predictor of mortality among medically ill elderly patients: A 2-Year longitudinal study. Journal of Health Psychology, 9, 713-730. DOI: 10.1177/1359105304045366

This article is protected by copyright. All rights reserved. 
Moors, A., Ellsworth, P., Scherer, K. R., \& Frijda, N. (2013). Appraisal theories of emotion: State of the art and future development. Emotion Review, 5, 119-124. DOI: 10.1177/1754073912468165

Nisbett, R. E., \& Wilson, T. D. (1977). Telling more than we can know: Verbal reports on mental processes. Psychological Review, 84, 231-259. DOI: 10.1037/0033-295X.84.3.231

Orne, M. T. (1962). On the social psychology of the psychological experiment: With particular reference to demand characteristics and their implications. American Psychologist, 17, 776783. DOI: $10.1037 / \mathrm{h} 0043424$

Pargament, K. I., Ensing, D. S., Falgout, K., Olsen, H., Reilly, B., Van Haitsma, K., \& Warren, R. (1990). God help me:(I): Religious coping efforts as predictors of the outcomes to significant negative life events. American Journal of Community Psychology, 18, 793-824. DOI: 10.1007/BF00938065

Pargament, K. I., Olsen, H., Reilly, B., Falgout, K., Ensing, D. S., \& Van Haitsma, K. (1992). God help me (II): The relationship of religious orientations to religious coping with negative life events. Journal for the Scientific Study of Religion, 31, 504-513. DOI: 10.2307/1386859

Piedmont, R. L. (2001). Spiritual transcendence and the scientific study of spirituality. Journal of Rehabilitation, 67, 4-14.

Ptacek, J. T., Smith, R. E., Espe, K., \& Raffety, B. (1994). Limited correspondence between daily coping reports and restrospective coping recall. Psychological Assessment, 6, 41-49. DOI: 10.1037/1040-3590.6.1.41

Ramsay, J. E., Tong, E. M., Pang, J. S., \& Chowdhury, A. (2016). A Puzzle Unsolved: Failure to Observe Different Effects of God and Religion Primes on Intergroup Attitudes. PloS one, 11, e0147178. DOI: 10.1371/journal.pone.0147178

This article is protected by copyright. All rights reserved. 
Ray, S. D., Lockman, J. D., Jones, E. J., \& Kelly, M. H. (2015). Attributions to God and Satan about lifealtering events. Psychology of Religion and Spirituality, 7, 60-69. DOI: 10.1037/a0037884

Riggio, H. R., Uhalt, J., \& Matthies, B. K. (2014). Unanswered prayers: religiosity and the God-serving bias. The Journal of Social Psychology, 154, 491-514. DOI: 10.1080/00224545.2014.953024

Ryan, R. M., \& Deci, E. L. (2000). Self-determination theory and the facilitation of intrinsic motivation, social development, and well-being. American Psychologist, 55, 68-78. DOI: 10.1037/0003-066X.55.1.68

Sandvik, E., Diener, E., \& Seidlitz, L. (1993). Subjective Well-Being: The Convergence and Stability of Self-Report and Non-Self-Report Measures. Journal of Personality, 61(3), 317-342. https://doi.org/10.1111/j.1467-6494.1993.tb00283.x

Seybold, K. S., \& Hill, P. C. (2001). The role of religion and spirituality in mental and physical health. Current Directions in Psychological Science, 10, 21-24. DOI: 10.1111/1467-8721.00106

Smith, C., \& Denton, M. L. (2005). Soul searching: The religious and spiritual lives of American teenagers. New York, NY: Oxford University Press. doi:10.1093/019518095X.001.0001

Steger, M. F., \& Frazier, P. (2005). Meaning in Life: One Link in the Chain From Religiousness to WellBeing. Journal of Counseling Psychology, 52, 574. DOI: 10.1037/0022-0167.52.4.574

Stone, A. A., \& Shiffman, S. (1994). Ecological momentary assessment (EMA) in behavorial medicine. Annals of Behavioral Medicine, 16, 199-202.

Van Cappellen, P., \& Saroglou, V. (2012). Awe activates religious and spiritual feelings and behavioral intentions. Psychology of Religion and Spirituality, 4, 223-236. DOI: 10.1037/a0025986

Van Cappellen, P., Saroglou, V., Iweins, C., Piovesana, M., \& Fredrickson, B. L. (2013). Selftranscendent positive emotions increase spirituality through basic world assumptions. Cognition \& Emotion, 27, 1378-1394. DOI: 10.1080/02699931.2013.787395

This article is protected by copyright. All rights reserved. 
Van Cappellen, P., Toth-Gauthier, M., Saroglou, V., \& Fredrickson, B. L. (2016). Religion and wellbeing: The mediating role of positive emotions. Journal of Happiness Studies, 17, 485-505. DOI: 10.1007/s10902-014-9605-5

Watkins, P. C., Woodward, K., Stone, T., \& Kolts, R. L. (2003). Gratitude and happiness: Development of a measure of gratitude, and relationships with subjective well-being. Social Behavior and Personality: an international journal, 31, 431-451. DOI: 10.2224/sbp.2003.31.5.431

Wood, A. M., Froh, J. J., \& Geraghty, A. W. (2010). Gratitude and well-being: A review and theoretical integration. Clinical Psychology Review, 30, 890-905. DOI: 10.1016/j.cpr.2010.03.005

Yilmaz, O., Karadöller, D. Z., \& Sofuoglu, G. (2016). Analytic Thinking, Religion, and Prejudice: An Experimental Test of the Dual-Process Model of Mind. The International Journal for the Psychology of Religion, 26, 1-10. DOI: 10.1080/10508619.2016.1151117

This article is protected by copyright. All rights reserved. 
Table 1

Descriptive Statistics and Correlations of Study 1 Variables

\begin{tabular}{|c|c|c|c|c|c|c|}
\hline Score & & 1 & 2 & 3 & 4 & 5 \\
\hline 1. & Religiosity & - & $.524 * *$ & $.213^{* *}$ & $.254 * *$ & $.281 * *$ \\
\hline 2. & Teleology & & - & $.315^{* *}$ & $.441 * *$ & .149 \\
\hline 3. & Contentment & & & - & $.913^{*}$ & $.573 * *$ \\
\hline 4. & Gratitude & & & & - & $.550 * *$ \\
\hline 5. & Well-Being & & & & & - \\
\hline 6. & $M$ & 0 & 5.092 & 3.199 & 3.406 & 4.52 \\
\hline 7. & $S D$ & .892 & 1.327 & .894 & .857 & 1.455 \\
\hline
\end{tabular}

Note. $^{* *}=$ significant at $p<.01,{ }^{*}=$ significant at $p<.05$. All $\mathrm{N}=120$.

Table 2

Summary Statistics for the Serial Mediation Model Tested in Study 1

\begin{tabular}{|c|c|c|c|c|c|c|c|}
\hline \multirow{2}{*}{ Well-Being } & & \multicolumn{6}{|c|}{$95 \% \mathrm{Cl}$} \\
\hline & & Coeff. & SE & $t$ & $p$ & $\mathrm{LL}$ & UL \\
\hline \multirow{6}{*}{$\begin{array}{l}\text { Direct } \\
\text { Effects }\end{array}$} & $a$ & .78 & .12 & 6.68 & .00 & .55 & 1.01 \\
\hline & $b$ & .23 & .06 & 3.59 & .00 & .10 & .36 \\
\hline & $c$ & .05 & .10 & .50 & .61 & -.14 & .24 \\
\hline & $d$ & 1.01 & .13 & 7.53 & .00 & .75 & 1.28 \\
\hline & $e$ & -.23 & .10 & -2.33 & .02 & -.43 & -.03 \\
\hline & $f$ & .41 & .14 & 2.90 & .00 & .13 & .68 \\
\hline \multirow{5}{*}{$\begin{array}{l}\text { Indirect } \\
\text { Effects }\end{array}$} & $a^{*} e$ & -.18 & .08 & & & -.36 & -.05 \\
\hline & $c^{*} d$ & .05 & .09 & & & -.13 & .24 \\
\hline & $a * b * d$ & .18 & .06 & & & .08 & .35 \\
\hline & $c * d$ & .03 & .07 & & & -.08 & .18 \\
\hline & $a * b * d$ & .12 & .05 & & & .05 & .26 \\
\hline
\end{tabular}

Note. . Coeff. = coefficient. $\mathrm{SE}=$ standard error. $\mathrm{Cl}=$ confidence interval. $\mathrm{LL}=$ lower limit. $\mathrm{UL}=$ upper limit. Standard error and confidence intervals for indirect effects are bootstrap estimates.

This article is protected by copyright. All rights reserved. 
Table 3

Descriptive Statistics for Key Study 2 and Study 3 Variables

$\begin{array}{lll}\text { Full Sample } & \text { Religious } & \text { Non-Religious } \\ & \text { Participants } & \text { Participants }\end{array}$

\begin{tabular}{llllll}
\hline$M$ & $S D$ & $M$ & $S D$ & $M$ & $S D$
\end{tabular}

Baseline Measures

Communal Religious Practice

6.22

2.91

6.80

2.81

3.37

1.22

Private Religious Practice

15.56

9.09

17.40

8.70

6.63

4.49

Daily Spiritual Experiences

22.06

10.15

24.72

8.91

9.21

4.26

Religious

Values/Beliefs

$\begin{array}{llllll}7.59 & 1.92 & 8.03 & 1.58 & 5.47 & 2.01\end{array}$

Study 2 EMA Measures

Momentary Teleological

4.64

1.51

4.78

1.46

3.95

1.56

Explanations

Momentary Positive Emotions

3.20

1.05

3.23

1.04

3.05

1.07

Study 3 EMA Measures

Momentary Teleological

Explanations

4.57

1.53

4.78

1.49

3.75

1.41

Momentary Positive

3.01

1.03

3.08

1.03

2.72

1.00

Fmotions

Momentary

Well-Being

$\begin{array}{llllll}4.62 & 1.37 & 4.66 & 1.36 & 4.44 & 1.37\end{array}$

This article is protected by copyright. All rights reserved. 
Table 4

Summary Statistics for the Multi-Level Mediation Model Tested in Studies 2 and 3

Study 2

$95 \% \mathrm{Cl}$

\begin{tabular}{llllllll}
\hline & & Coeff. & SE & $Z$ & $p$ & LL & UL \\
\hline \multirow{2}{*}{ Direct Effects } & $a$ & .71 & .11 & 6.60 & .00 & .50 & .93 \\
& $b$ & .17 & .04 & 4.18 & .00 & .09 & .25 \\
& $c$ & -.05 & .05 & -.86 & .39 & -.15 & .06 \\
\hline Indirect effect & $a^{*} b$ & .12 & .04 & 3.53 & .00 & .06 & .19
\end{tabular}

Study 3

$95 \% \mathrm{Cl}$

\begin{tabular}{llllllll}
\hline & & Coeff. & SE & $Z$ & $p$ & LL & UL \\
\hline \multirow{5}{*}{ Direct Effects } & $a$ & .75 & .14 & 5.54 & .00 & .49 & 1.02 \\
& $b$ & .25 & .06 & 4.32 & .00 & .14 & .37 \\
& $d$ & -.05 & .08 & -.61 & .54 & -.21 & .11 \\
& $e$ & 1.37 & .16 & 8.69 & .00 & 1.06 & 1.68 \\
& & -.04 & .08 & -.45 & .65 & -.19 & .12 \\
& $f$ & -.01 & .09 & -.11 & .91 & -.19 & .17 \\
\hline \multirow{5}{*}{ Indirect Effects } & $c^{*} d$ & .19 & .06 & 3.41 & .00 & .08 & .30 \\
& $a * e$ & .09 & 3.90 & .00 & .17 & .52 \\
& $a * b * d$ & .26 & .08 & 3.19 & .00 & .10 & .42
\end{tabular}

Note. Coeff. $=$ coefficient. $\mathrm{SE}=$ standard error. $\mathrm{Cl}=$ confidence interval. $\mathrm{LL}=$ lower limit. $\mathrm{UL}=$ upper limit.

This article is protected by copyright. All rights reserved. 


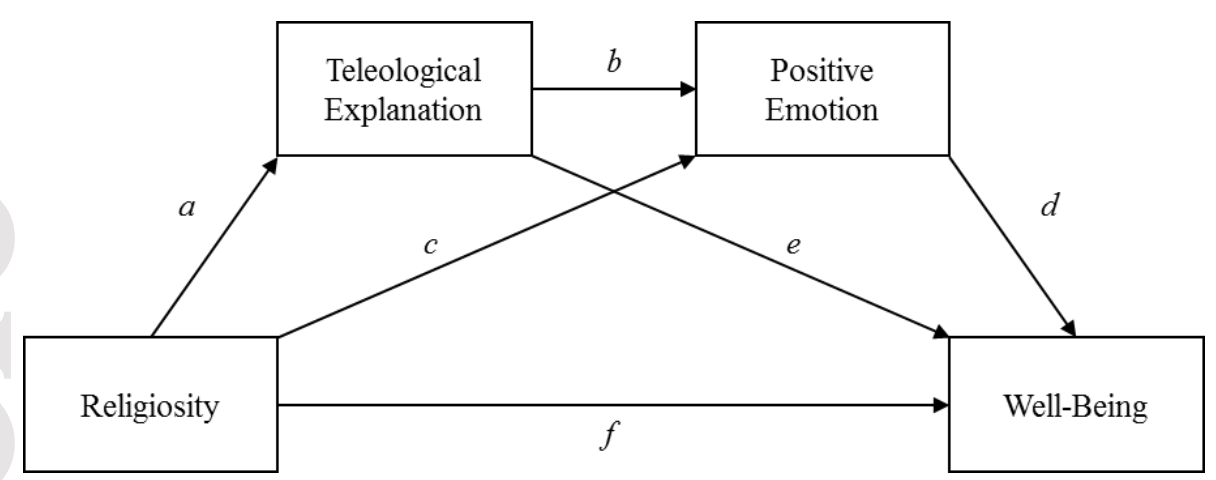

Figure 1. Depiction of the serial mediation models tested in study 1.

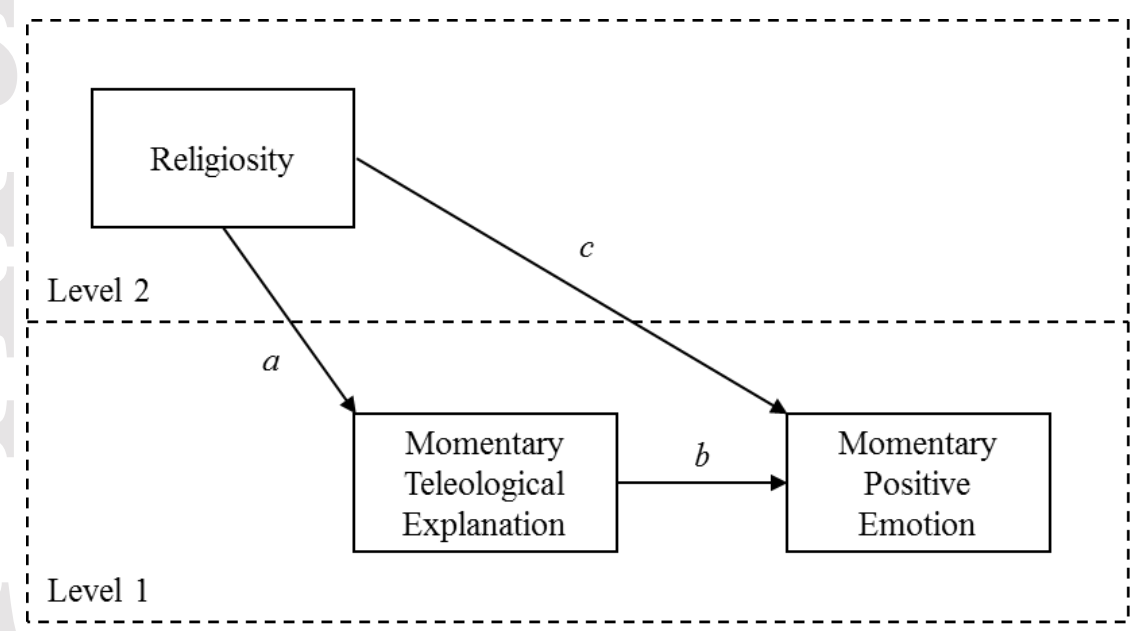

Figure 2. Depiction of the mediation model tested in study 2.

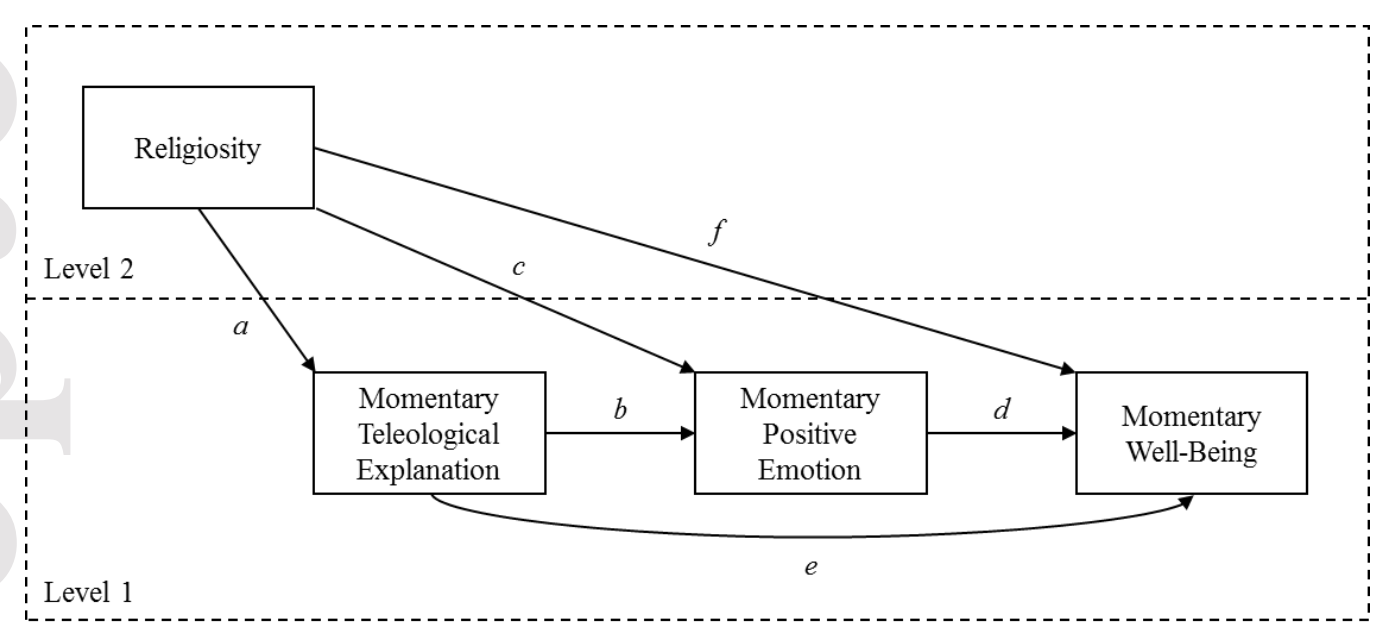

Figure 3. Depiction of the serial mediation model tested in study 3.

This article is protected by copyright. All rights reserved. 